CZASOPISMO INŻYNIERII LĄDOWEJ, ŚRODOWISKA I ARCHITEKTURY JOURNAL OF CIVIL ENGINEERING, ENVIRONMENT AND ARCHITECTURE JCEEA, t. XXXIII, z. 63 (1/I/16), styczeń-marzec 2016, s. 247-254

\author{
Jacek DOMSKI ${ }^{1}$
}

\title{
UGIĘCIE DŁUGOTRWAŁE ELEMENTÓW FIBROBETONOWYCH WYTWORZONYCH NA BAZIE KRUSZYWA ODPADOWEGO
}

\begin{abstract}
Zrównoważony Rozwój powinien dotyczyć każdej dziedziny gospodarki, również budownictwa, dlatego też podjęta w artykule tematyka jest szczególnie ważna dla obszarów północnej Polski. Artykuł prezentuje wyniki badań długotrwałych elementów wykonanych z betonu na bazie kruszywa odpadowego, zalegającego na hałdach kopalnianych, wzbogaconego dodatkiem w postaci minimalnej ilości włókien stalowych. Zakres prezentowanych badań towarzyszących obejmował wytrzymałość na ściskanie, moduł sprężystości oraz odkształcenia skurczowe i pełzania, wykonane na próbkach walcowych o średnicy $15 \mathrm{~cm}$ i wysokości $30 \mathrm{~cm}$. Badania podstawowe przeprowadzono na specjalnie zaprojektowanych, skonstruowanych i skalibrowanych układach dźwigniowych, w których umieszczono 8 belek o wymiarach $0,15 \times 0,20 \times 3,3 \mathrm{~m}$. Belki i część walców obciążono po 28 dniach dojrzewania betonu i utrzymywano stałe obciążenie $(6 \mathrm{kN} \cdot \mathrm{m}$ dla belek i $1 / 3$ wytrzymałości na ściskanie dla walców w próbie pełzania) przez okres 365 dni. Zakres prezentowanych w niniejszym artykule badań podstawowych ograniczono jedynie do ugięcia elementów belkowych, jednak ich analizę przeprowadzono w oparciu o normowe $\mathrm{i}$ autorskie metody obliczeń. $\mathrm{W}$ analizie wykorzystano aktualną metodę normową wg PN-EN-1992-1-1 i autorskie metody Tana wraz z różnymi zespołami oraz Bywalskiego. Na podstawie przeprowadzonych porównań i analiz stwierdzono, że wykorzystane metody szacowania wartości ugięcia długotrwałego są wrażliwe na stopień zbrojenia podłużnego belek. Część z nich wiernie odzwierciedla ugięcie dla belek o niskim stopniu zbrojenia (propozycja Bywalskiego), natomiast dla części lepszą zgodność uzyskano dla belek zbrojonych ekonomicznie - jedna z propozycji Tana z zespołem. Jednocześnie należy zauważyć, że metoda normowa wg PN-EN-1992-1-1 może być stosowana do określania ugięcia elementów belkowych wykonanych na bazie kruszywa odpadowego i włókien stalowych, jednak daje ona zawyżone wartości.
\end{abstract}

Słowa kluczowe: piasek odpadowy, włókna stalowe, belka, ugięcie długotrwałe, pełzanie, skurcz

\footnotetext{
${ }^{1}$ Jacek Domski, Politechnika Koszalińska, ul. Śniadeckich 2, 75-453 Koszalin, tel. 943486730 , e-mail: domski@wilsig.tu.koszalin.pl
} 


\section{Wprowadzenie}

\subsection{Opis problemu}

Środowisko naturalne jest naszym największym dobrem. Dlatego też powinno ono wpływać w coraz większym stopniu na racjonalną eksploatację złóż surowców mineralnych wykorzystywanych m.in. w produkcji kruszyw budowlanych. Szacuje się, że światowe roczne zużycie kruszywa do betonu na osobę to około 3 tony. W obszarze Polski północnej występują przede wszystkim złoża piaszczyste (około 100 milionów ton) i stanowią one około 30 \% krajowych złóż surowców do produkcji kruszyw. W kopalniach kruszyw tego regionu około $43 \%$ urobku poddaje się hydroklasyfikacji, uzyskując żwir w ilości $20 \div 25 \%$ całości pospółki. Piasek, stanowiący $75 \div 80 \%$ pozostałości z procesu hydrosortowania, traktowany jest niesłusznie jako odpad (rys. 1.). W piasku tym, wraz ze wzrostem stopnia rozdrobnienia ziaren, zwiększa się udział kwarcu, a maleje zawartość pozostałych grup mineralno-petrograficznych, a ponadto jest on w znacznym stopniu pozbawiony substancji ilastych. Właściwości tego surowca skłaniają do wykorzystania go do produkcji betonów o specyficznych właściwościach, uzyskanych np. poprzez dodatek zbrojenia rozproszonego $[8,11,14]$.


Rys. 1. Hałdy piasku w istniejącej (a) i zlikwidowanej (b) kopalni kruszyw (obszar północnej Polski)

Fig. 1.Waste sand dumps in operative (a) and inoperative (b) aggregate mine (northern Poland area)

\subsection{Przegląd literaturowy}

Obliczanie ugięcia elementów belkowych wymaga przede wszystkim jak najwierniejszego określenia sztywności $\mathrm{w}$ analizowanym przekroju. Jej zmiana pod wpływem obciążenia jest trudna do określenia, gdyż ma na nią wpływ znaczna liczba niezależnych parametrów, takich jak moduł sprężystości, moment bezwładności przekroju, czy stopień zbrojenia podłużnego. Problem ten dotyczy belek wykonanych z różnych materiałów, w tym i z betonu modyfikowanego włóknami. Istnieje kilka metod obliczania ugięcia fibrobetonowych 
elementów belkowych $[2,3,6,9,12,15,16,18]$, jednak tylko część z nich zawiera propozycję określania ugięcia wywołanego obciążeniem działającym długotrwale $[4,9,18,19,20]$. Dodatkowym problemem jest fakt, że wymienione wyżej metody obliczania stanu granicznego ugięcia belek z dodatkiem włókien stalowych dotyczą elementów fibrobetonowych, wykonanych na bazie betonu z kruszywem o uziarnieniu powyżej $2 \mathrm{~mm}$. W niniejszym artykule zweryfikowano przydatność wybranych metod obliczania ugięcia dla belek wykonanych z fibrobetonu na bazie kruszywa odpadowego (piasku do $2 \mathrm{~mm}$ ).

\section{Program i metodyka badań}

\subsection{Skład mieszanek betonowych i wykonanie elementów próbnych}

Skład mieszanki betonowej ustalono bazując na doświadczalnej zależności pomiędzy rzeczywistą objętością wody i porów w mieszance betonowej, a właściwościami betonu piaskowego. Następnie zmodyfikowano ustalony skład mieszanki, poprzez dodanie odpowiedniej ilości superplastyfikatora (FM 34) oraz włókien stalowych (o długości $30 \mathrm{~mm}$ i średnicy 0,55 mm [13]). Ilość włókien ustalono na poziomie spełniającym minimalny warunek klasyfikacyjny zawarty w MC2010 [17] i była taka sama jak w [7]. Zawartość superplastyfikatora regulowano tak, aby otrzymać mieszankę o konsystencji plastycznej, zgodnie z [1]. W rezultacie otrzymano beton odpowiadający klasie C30/37 według EC2 [10]. Dodatkowo wykonano serię elementów z betonu zwykłego (towarowego), na bazie cementu CEM I 32,5 R i plastyfikatora Pantarhit ${ }^{\circledR} 45$ BV. Jego skład został zaprojektowany przez lokalnego producenta (tabela $\mathrm{nr} 1$ ).

Tabela 1. Składy mieszanek betonowych

Table 1. Mixture composition

\begin{tabular}{|c|c|c|c|c|c|c|c|}
\hline \multirow{2}{*}{$\begin{array}{c}\text { Serie } \\
\text { próbne }\end{array}$} & \multicolumn{3}{|c|}{ Kruszywo [kg] } & Cement & Woda & BV/FM & Włókna \\
\cline { 2 - 8 } & $(0-2)$ & $(2-8)$ & $(8-16)$ & {$[\mathrm{kg}]$} & {$\left[\mathrm{dm}^{3}\right]$} & {$\left[\mathrm{dm}^{3}\right]$} & {$[\mathrm{kg}]$} \\
\hline B5 & 646,0 & 576,0 & 523,0 & 410,0 & 188,0 & 1,64 & - \\
\hline $\begin{array}{l}\text { B6, B7, } \\
\text { B8 }\end{array}$ & 1855,0 & - & - & 378,0 & 140,0 & 3,51 & 34,0 \\
\hline
\end{tabular}

Elementy próbne wykonywano seriami ( $\mathrm{w}$ sezonie jesienno-zimowym $\mathrm{w}$ pomieszczeniu, w którym temperatura powietrza wynosiła około $20^{\circ} \mathrm{C}$ ), utrzymując jednakowy reżim technologiczny. Przez pierwsze 24 godziny (do chwili rozformowania), jak i przez kolejne 6 dni, próbki dojrzewały w warunkach podwyższonej wilgotności, tj. szczelnie przykryte folią. Po siedmiu dniach dojrzewania elementy próbne transportowano do hali laboratoryjnej, gdzie znajdowały się do zakończenia badań. Temperatura powietrza w hali wahała się od 14 do $25^{\circ} \mathrm{C}$, natomiast wilgotność powietrza wynosiła od 14 do $75 \%$. 


\subsection{Program i metodyka badań}

Specjalnie skonstruowany i skalibrowany układ dźwigniowy posłużył do obciążenia elementów belkowych stałą wartością obciążenia równą $6 \mathrm{kN} \cdot \mathrm{m}$. Do pomiaru ugięcia zastosowano czujniki zegarowe (o dokładności $0,01 \mathrm{~mm}$ ), usytuowane pod belką, w charakterystycznych miejscach, tj.: przy podporach, w osi obciążeń skupionych i w środku rozpiętości belki (rys. 2a).
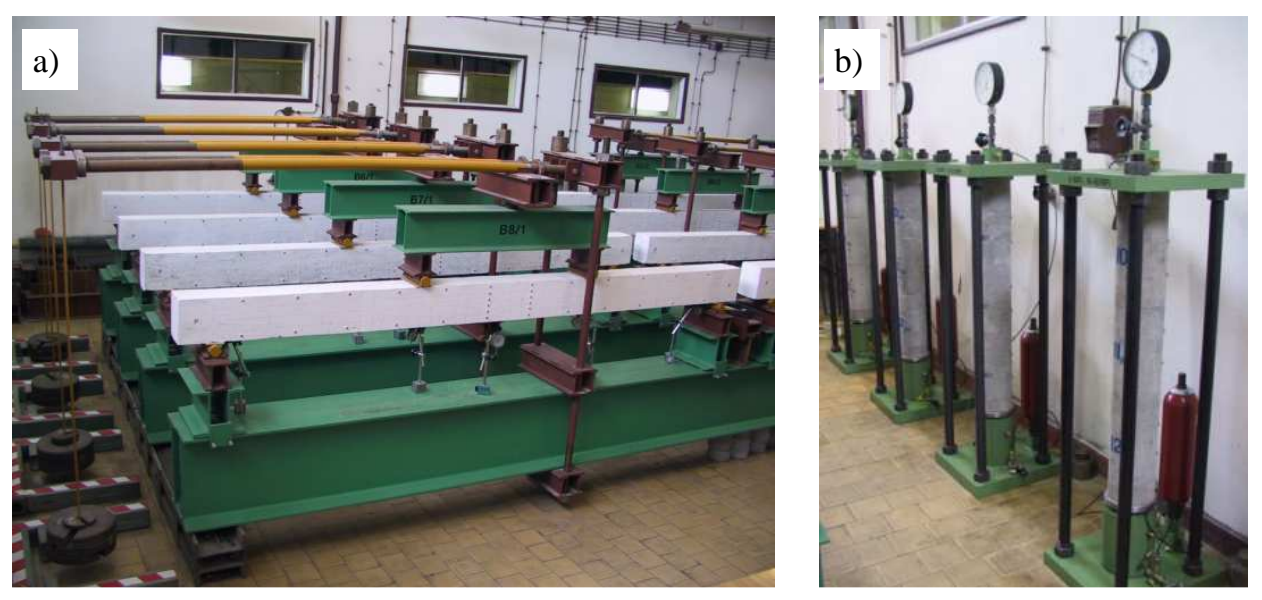

Rys. 2. Stanowiska i elementy próbne podczas badań długotrwałych: a) ugięcia belek, b) odkształcenia pełzania próbek walcowych

Fig. 2. Work stands and specimens during long-term study of: a) beam deflection, b) creep strain of cylindrical specimens

Badanie ugięcia prowadzono na belkach o wymiarach $150 \times 200 \times 3300 \mathrm{~mm}$, pracujących w schemacie czteropunktowego (co 1,0 m) zginania, przez okres 1 roku. Elementy próbne wykonano w 4 seriach, zróżnicowanych pod względem: rodzaju mieszanki betonowej (beton zwykły i fibrokompozyt) oraz stopnia zbrojenia podłużnego (rozciąganego) elementów belkowych $(0,6 \% ; 0,9 \%$; $1,3 \%$ ). Jednakowe dla wszystkich belek było zbrojenie ściskane, w postaci dwóch prętów o średnicy $8 \mathrm{~mm}$ oraz dwucięte strzemiona, prostopadłe do osi elementu (o średnicy 4,5 $\mathrm{mm}$ ), rozmieszczone co $130 \mathrm{~mm}$. Zbrojenie podłużne belek wykonano ze stali żebrowanej (gatunku 34GS), zaś zbrojenie poprzeczne ze stali gładkiej (gatunku St3SX-b). Każda seria elementów próbnych składała się z dwóch belek oraz 12 walców (o średnicy $150 \mathrm{~mm}$ i wysokości $300 \mathrm{~mm}$ ), na których określono wytrzymałość na ściskanie, moduł sprężystości oraz odkształcenia skurczowe i pełzania ( 3 próbki na każdą cechę). Badania wytrzymałościowe elementów drobnowymiarowych przeprowadzono po 28 dniach od ich wykonania. Pomiar odkształceń skurczowych rozpoczynano po 48 godzinach od zabetonowania elementów próbnych. Do 28 dnia odczyty dokonywano codziennie, a następnie w terminach zgodnych z pomiarami pełzania. Badania pełzania 
rozpoczęto po 28 dniach dojrzewania próbek i dokonywano kolejne odczyty w terminach: przez pierwsze siedem dni codziennie, raz w tygodniu przez kolejne 12 tygodni oraz raz w miesiącu, aż do 365 dnia badania. Jednorazowo w pełzarce umieszczano współosiowo trzy próbki walcowe (rys 2b.).

\section{Wyniki badań $\mathrm{i}$ ich analiza}

Pomierzone odkształcenia pełzania skorygowano (pomniejszono) o odpowiednią wartość odkształceń skurczowych i porównano je z wartościami obliczonymi wg EC2 [10]. Średnie odkształcenia dwóch serii pokazano na rys. 3.

a)



b)



Rys. 3. Średnie odkształcenia pełzania dla serii: a) B5, b) B7

Fig. 3. Average creep strain for series: a) B5, b) B7

Wartości ostatecznych odkształceń pełzania, obliczone wg EC2 [10], są wyższe od wartości doświadczalnych dla wszystkich badanych serii. Największe odkształcenia pełzania (przy tym samym poziomie obciążenia) uzyskano dla elementów wykonanych z betonu zwykłego (rys 3a). Określone z badań wartości współczynnika pełzania dla analizowanych fibrobetonów, przy poziomie obciążenia $1 / 3 \mathrm{f}_{\mathrm{cm}}$, po roku obciążenia wynosiły maksymalnie 1,89 zaś dla betonu zwykłego 2,42.

Przemieszczenia w punktach charakterystycznych belek określono w kilkunastu terminach badań. Wartości ugięcia wyznaczono w każdym z analizowanych dni, po uwzględnieniu przemieszczeń przy podporach, rozumianych jako ich osiadanie. Wykresy ugięć $\mathrm{w}$ środku rozpiętości belek, o różnym stopniu zbrojenia $(0,6 \%$ - B6; 0,9 \% - B5 i B7; 1,3 \% - B8), w porównaniu z wybranymi metodami obliczeń przedstawiono na rysunku 4.

Jak wynika z wykresów (rys. 4.) wyniki obliczeń ugięcia wg metody [18] znacznie odbiegają od wartości ugięć uzyskanych z badań. Wartości teoretyczne ugięć w tym przypadku są niższe niż wartości uzyskane z badań, co może sugerować brak przydatności tej metody do oceny ugięć badanych belek. Analizując kolejne wyniki ugięć, uzyskane wg propozycji [4], można zauważyć, że najle- 


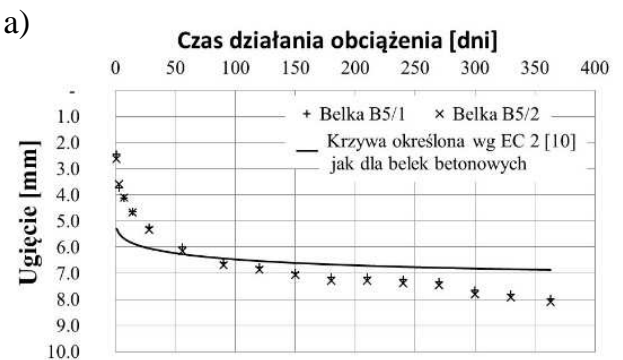

c)



b)

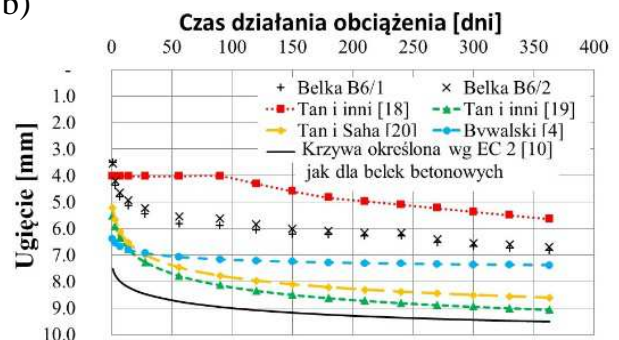

d)

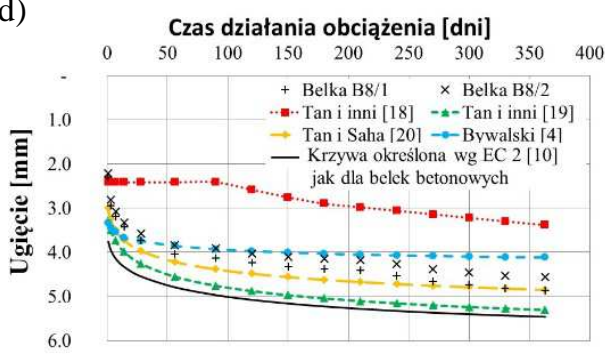

Rys. 4. Ugięcie w środku rozpiętości belek serii: a) B5, b) B6, c) B7, d) B8

Fig. 4. Midspan deflection of beams for series: a) B5, b) B6, c) B7, d) B8

piej opisuje ona zjawisko dla belek o najniższym stopniu zbrojenia. Kolejne dwie metody, wg [19] i [20], dość wiernie odzwierciedlają przebieg ugięcia belek, w których zastosowano stopień zbrojenia na poziomie ekonomicznym. Na podstawie metody normowej [10] uzyskano wyższe (w stosunku do wyników z badań) wartości ugięć, co pośrednio dowodzi, że należy obliczeniowo uwzględniać wpływ włókien stalowych na redukcję ugięć [5, 8].

\section{Podsumowanie}

Brak dodatkowych wytycznych dotyczących obliczania ugięcia elementów fibrobetonowych $\mathrm{w}$ aktualnej normie żelbetowej [10], jak $\mathrm{i}$ w pre-normie MC2010 [17] skutkuje tym, że uwzględnianie pozytywnego wpływu włókien jest i będzie utrudnione w praktyce projektowej. Uwaga ta dotyczy tym bardziej elementów żelbetowych wykonanych na bazie kruszywa odpadowego i włókien stalowych. W tym względzie przydatne mogą być metod autorskie, które dość dobrze szacują ugięcia badanych elementów. Jak wynika z przeprowadzonych analiz, najmniejsze różnice ugięć obliczonych i określonych z badań daje metoda Tana i Saha [20]. Należy jednak mieć na uwadze, że wniosek ten dotyczy belek fibrobetonowych na bazie kruszywa odpadowego i został wyciągnięty na stosunkowo niewielkiej liczbie przebadanych belek. 


\section{Literatura}

[1] ACI 544.3R-93 Guide for specifying, proportioning, mixing, placing and finishing steel fiber reinforced concrete, 1998.

[2] Alsayed S.H.: Flexural deflection of reinforced fibrous concrete beams, ACI Structural Journal, January-February, 1993, s. 72-76.

[3] Ashour S. A., Wafa F. F.: Flexural behaviour of high-strength fibre reinforced concrete beams, ACI Structural Journal, May-June, 1993, s. 279-287.

[4] Bywalski Cz.: Ugięcia długotrwale obciążonych belek żelbetowych modyfikowanych włóknami stalowymi, Rozprawa doktorska, Instytut Budownictwa Politechniki Wrocławskiej 2009.

[5] Bywalski Cz., Kamiński M.: Badania doraźnych i długotrwałych ugięć belek fibrobetonowych, Inżynieria i Budownictwo, nr 12, 2010, s. 701-703.

[6] Craig R.: Flexural behaviour and design of reinforced fiber concrete members, Fiber reinforced concrete properties and applications, SP-105 American Concrete Institute 1987 , s. 517-563.

[7] Domski J.: A blurred border between ordinary concrete and SFRC, Construction and Building Materials, vol. 112, 2016, s. 247-252.

[8] Domski J.: Long-term study on fibre reinforced fine aggregate concrete beams based on waste sand, Annual Set The Environmental Protection, vol. 17, 2015, s. $188-199$.

[9] Ezeldin A. S., Shiah T.W.: Analytical immediate and long-term deflections of fibrereinforced concrete beams, ASCE Journal of Structural Engineering, April, 1995, s. 727-738.

[10] Eurokod 2: PN-EN-1992-1-1:2004 Projektowanie konstrukcji z betonu - Część 1-1: Reguły ogólne i reguły dla budynków.

[11] Głodkowska W., Laskowska-Bury J.: Piaski odpadowe jako wartościowe kruszywo do fibrokompozytów, Annual Set The Environment Protection. vol. 17, 2015, s. 507-525.

[12] Hsu C.-T. T., He R. L., Ezeldin A. S.: Load-deformation behaviour of steel fibre reinforced concrete beams, ACI Structural Journal, November-December, 1992, s. $650-657$.

[13] Katzer J., Domski J.: Optimization of fibre reinforcement for waste aggregate cement composite, Construction and Building Materials, vol. 38, 2013, s. 790-795.

[14] Ponikiewski T., Katzer J.: Mechanical characteristics of green SCC modified by steel and polymer fibres, Annual Set The Environmental Protection, vol. 16, 2014, s. 173-185.

[15] Liqiu G., Guofan Z.: Analysis of complete moment-curvature curve of concrete beams reinforced with steel bars and steel fibers, Congress by RILEM 1987, tom 2 , s. 706-713.

[16] Lim T. Y., Paramasivam P., Lee S. L.: Behaviour of reinforced steel-fiber-concrete beams in flexural, ASCE Journal of Structural Engineering, December, 1987, s. 2439-2458.

[17] Model Code. First complete draft red. Lausanne: International Federation for Structural Concrete, fib Bulletin 55, 2010. 
[18] Tan K.-H., Paramsivam P., Tan K.-C.: Instantaneous and long-term deflections of steel fibre reinforced concrete beams, ACI Structural Journal, July-August, 1994, s. 384-393.

[19] Tan K.-H., Paramsivam P., Tan K.-C.: Creep and shrinkage deflections of RC beams with steel fibers, Journal of Materials in Civil Engineering, vol. 6, 1994, s. 474-494.

[20] Tan K.-H., Saha, M.-K.: Ten-year study on steel fiber-reinforced concrete beams under sustained loads, ACI Structural Journal, vol. 102, 2005, s. 472-480.

\section{LONG - TERM DEFLECTION OF FIBER - REINFORCED CONCRETE ELEMENTS MADE OUT OF WASTE AGGREGATE}

\section{S u m m a r y}

Sustainable Ecological Development should concern every economy branch including civil engineering. That is the reason why the subject matter of the article is particularly important for northern Poland area, where numerous waste sand dumps are located. The article presents results of the long - term research on concrete specimens made out of waste aggregate lying in mine dumps, enriched with addition of minimal quantity of steel fibers. The scope of presented accompanying research included compressive strength, modulus of elasticity and both creep and shrinkage strains made on cylindrical specimens of $15 \mathrm{~cm}$ in diameter and $30 \mathrm{~cm}$ in heights. The basic research was conducted in specifically designed, built and calibrated lever system, in which there were placed 8 beams with dimensions of $0.15 \times 0.20 \times 3.3 \mathrm{~m}$. The beams and several cylinders were loaded after 28 days of concrete curing and the loading was maintained on constant level $(6 \mathrm{kN} \cdot \mathrm{m}$ for beams and $1 / 3$ of compressive strength for cylinders in creep test) for the period of 365 days. The scope of presented basic research was limited only to beam specimens' deflection, although its analysis was made based on various methods of calculations: current method from EN-1992-1-1 norm and the ones developed by Tan with various teams and by Bywalski. On the grounds of made analysis and compared values it was stated that the methods of assessing values of long term deflection, are sensitive to the size of longitudinal reinforcement of beams. Part of them strongly reflects the value of deflection for beams weekly reinforced with fibers (Bywalski), some obtained higher compatibility for beams reinforced economically (Tan and his team). At the same time the method from EN-1992-1-1 also can be applied for determining deflection for beam elements made out of waste aggregate and steel fibers, however it produces overvalued results.

Keywords: waste sand, steel fibre, beam, long-term deflection, creep, shrinkage

Przestano do redakcji: 07.06.2016 $r$.

Przyjęto do druku: 30.06 .2016 r.

DOI: $10.7862 / r b .2016 .29$ 